\title{
PROPRIEDADE DE FLUXO E CARACTERÍSTICA DE ESCOABILIDADE DE RAÇÕES AVÍCOLAS PARA DIMENSIONAMENTO DE SILOS
}

\author{
Flow properties and flowability characteristics of poultry rations for design of silos
}

\author{
José Pinheiro Lopes Neto ${ }^{1}$, José Wallace Barbosa do Nascimento 2 , Valneide Rodrigues da Silva ${ }^{3}$, \\ Fernanda Fernandes de Melo Lopes $^{4}$
}

\begin{abstract}
RESUMO
O conhecimento das propriedades físicas e de fluxo dos produtos é de extrema importância no que se refere ao seu manuseio e processamento. Com a correta aplicação desses conhecimentos, é possível dimensionar de forma racional os sistemas de transporte e armazenagem utilizados, prevendo, assim, o tipo de fluxo ideal para cada operação. Este trabalho teve como objetivo determinar as propriedades físicas e de fluxo de três diferentes rações avícolas e avaliar suas influências nas características geométricas de tremonhas. $\mathrm{Na}$ obtenção dos dados, foi utilizado o aparelho de cisalhamento direto de translação (célula de cisalhamento de Jenike) e duas superfícies de parede: aço liso e rugoso. Para determinar o índice de fluxo (ff ) e o diâmetro mínimo do orifício de descarga (D), adotou-se a metodologia de Jenike enquanto que para o ângulo mínimo de inclinação da tremonha cônica, utilizou-se a metodologia de Enstad. Com base nos resultados obtidos, conclui-se que as Rações A e B foram classificadas como produtos coesivos enquanto que a Ração C apresentou os menores ângulos de inclinação da tremonha e maiores diâmetros de orifício de descarga.
\end{abstract}

Termos para indexação: Índice de fluxo, inclinação da tremonha, orifício de descarga.

\section{ABSTRACT}

The knowledge about the physical and flow properties of industrial powders is very important to their handling and processing. With the right application of this information, it's possible to design conveyors and storage systems to predict the ideal kind of flow for each operation. This work had the objective to determinate the physical and flow properties of different kinds of poultry rations and to evaluate their influences on geometric characteristics of hoppers. For that, it was used the direct shear apparatus based on Jenike shear cell and two friction surfaces: smooth and rough steel walls. To determinate the index flow (ff $\mathrm{c}_{\mathrm{c}}$ ) and minimum hopper opening diameter (D), was used the Jenike's methodology. For the minimum conical hopper angle, was used the mathematical method advised by British Standard BMHB. With the basis on obtained results, it's possible to affirm that A and B poultry rations were classified as cohesive flow while the B poultry ration had the minors conical hopper angle and the higher hopper opening diameter.

Index terms: Flow index, hopper inclination, opening discharge.

(Recebido em 9 de março de 2006 e aprovado em 13 de dezembro de 2006)

\section{INTRODUÇÃO}

A dinâmica dos produtos sólidos armazenáveis tem grande importância dentro dos processos industriais, e ainda, exerce influência em fatores como produtividade, eficiência e segurança. Com o acréscimo em quantidade e variedade de produtos sólidos armazenáveis produzidos pela indústria, existe a necessidade de informações quanto às suas características para manuseio e processamento, especialmente no caso dos produtos pulverulentos (Schubert, 1987). Knowlton, Carson, Klinzing et al. (1994), citam que a determinação dessas propriedades é importante por proporcionar conhecimento adequado às operações industriais como fluxo em tremonhas e silos, dosagem, transporte e empacotamento.

A ocorrência de obstruções no fluxo ou até mesmo sua completa ausência são problemas enfrentados pelas indústrias que manuseiam produtos pulverulentos, sejam eles orgânicos ou minerais. As propriedades físicas, de fluxo e condições externas como pressão, temperatura e umidade são as principais responsáveis por esse acontecimento (Teunou, Fitzpatrick e Synnot, 1999). O modo como o produto fluirá por gravidade em um silo é governado, por um lado, pelas propriedades de fluxo do produto e, por outro lado, pela geometria e estrutura da superfície da tremonha (Nóbrega, 2003).

\footnotetext{
Engenheiro Agrícola, Professor, Mestre - Universidade Federal de Campina Grande/UFCG - Unidade Acadêmica de Agronomia e Tecnologia de Alimentos/ UATA - Rua Coronel João Leite, 517, Centro - 58840-000 - Pombal, PB - lopesneto@gmail.com ${ }^{2}$ Engenheiro Agrícola, Professor, Doutor - Universidade Federal de Campina Grande/UFCG - Unidade Acadêmica de Engenharia Agrícola/UAEAg Avenida Aprígio Veloso, 882, Bodocongó - 58109-900 - Campina Grande, PB - wallace@deag.ufcg.edu.br

${ }^{3}$ Graduanda em Engenharia Agrícola - Universidade Federal de Campina Grande/UFCG - Avenida Aprígio Veloso, 882, Bodocongó - 58109-900 Campina Grande, PB - rval707@yahoo.com.br

${ }^{4}$ Engenheira Agrícola, Doutoranda em Engenharia de Processos - Universidade Federal de Campina Grande/UFCG - Avenida Aprígio Veloso, 882, Bodocongó - 58109-900 - Campina Grande, PB - fndmelo@gmail.com
} 
Geralmente, tais eventos estão relacionados ao desenvolvimento de um tipo inadequado de fluxo em virtude de possível coesão adquirida pelo produto, sob ação de esforços de compressão, capaz de formar um arco coesivo resistente o suficiente para suportar toda a carga do produto armazenado acima. Roberts (1987) descreve que sólidos podem transferir esforços de cisalhamento quando em condição estática; que quando comprimidos, desenvolvem coesão conservando sua forma e que os esforços de cisalhamento são dependentes das pressões atuantes no sólido.

Jenike (1964), pioneiro no estudo do comportamento de sólidos sob condições de armazenagem, definiu dois tipos básicos de fluxo: massa e funil. Defini-se fluxo de massa aquele onde o produto entra substancialmente em movimento em todas as partes do silo no momento do processo de descarregamento (ocorre quando as paredes da tremonha são suficientemente inclinadas e lisas e não existem abruptas transições). Em relação ao fluxo de funil, conceitua-se como sendo o tipo de fluxo onde apenas parte do produto entra em movimento através de um canal vertical (efeito tubo) formado no interior do silo. $\mathrm{O}$ efeito tubo ocorre em virtude de uma íntima associação entre produtos coesivos sendo descarregados em silos dotados de paredes de tremonhas rugosas e com elevado ângulo de inclinação com a vertical.

Conforme a British Materials Handling Board (1985), o fluxo de massa deve ser escolhido se: a vazão de descarga for controlada sem indevidas flutuações; a segregação nas partículas obtidas puder ser minimizada; o tempo de armazenamento no silo não for indevidamente prolongado ou se o local escolhido for adequado para tremonha cujos lados sejam muito inclinados. Somando a essas, pode-se citar que para produtos coesivos, é recomendável a utilização de fluxo de massa para prevenir a formação de arcos coesivos ou abóbadas.

Para o fluxo de funil, se recomenda caso: as vantagens acima citadas não forem de particular importância; se as flutuações na vazão de descarga, segregação de partículas e prolongado tempo de armazenagem não forem consideradas desvantagens; se o local escolhido apresentar restrições espaciais; se forem necessárias saídas múltiplas.

Jenike (1964) desenvolveu aparelho de cisalhamento direto para a determinação das propriedades de fluxos dos produtos armazenáveis denominado "Jenike Shear Cell" que é recomendável pela maioria das normas internacionais. Através de uma análise bi-dimensional dos esforços, é possível também o desenvolvimento de uma metodologia matemática capaz de determinar o ângulo mínimo da tremonha e dimensão de seu orifício de descarga para o fluxo de massa e funil para as formas cônica e de cunha.

Desta forma, é possível determinar a Função fluxo de um produto (FF) (Figura 1), através da construção de gráfico no qual é plotado a Tensão Não Confinada de Deslizamento $\left(\sigma_{\mathrm{C}}\right)$ versus Tensão Principal de Consolidação $\left(\sigma_{M}\right)$ a qual representa o esforço atuante no produto quando em situação de consolidação (Fitzpatrick, Barringer e Iqbal, 2004). Benink (1989) cita que a função fluxo é uma medida da escoabilidade do produto e pode ser utilizada para obtenção da abertura mínima de descarga do silo de forma a prevenir a obstrução do fluxo.

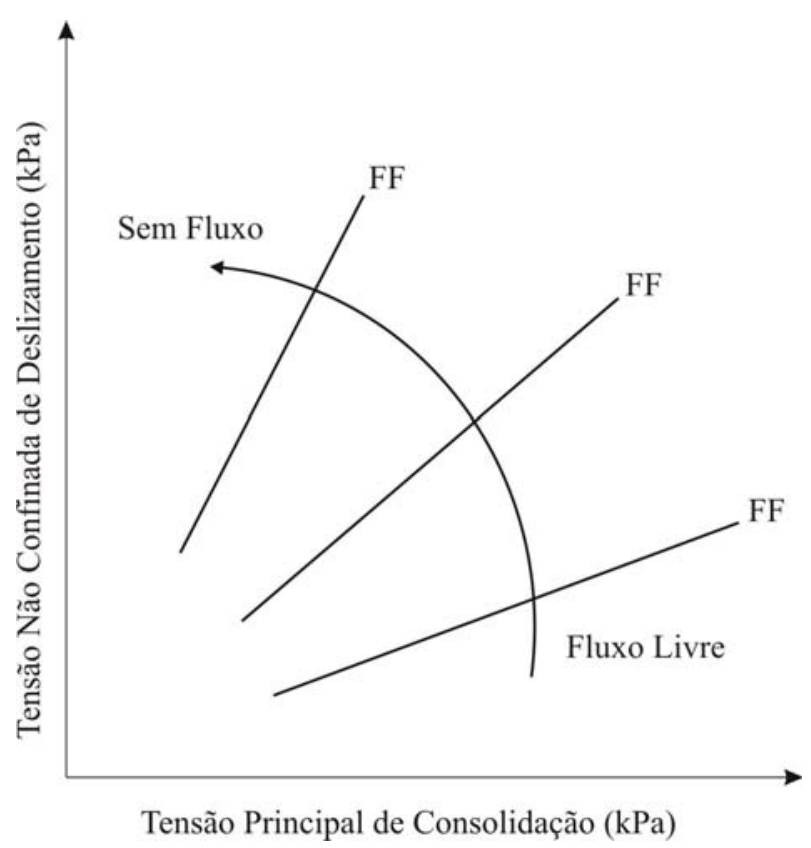

FIGURA 1 - Função Fluxo: "fluxo livre" versus "sem fluxo".

A curva mais próxima à condição ao eixo horizontal representa um produto de fluxo fácil enquanto que, seguindo uma direção anti-horária, tal produto tende a apresentar maior resistência ao escoamento. Outra particularidade importante é o Índice de fluxo ( $\mathrm{ff}_{c}$ ) o qual é definido como o inverso da inclinação de FF (Jenike, 1964) e pode variar de uma condição de ausência de fluxo até outra caracterizada como de fluxo livre. Jenike usou o ff ${ }_{c}$ para classificar os produtos armazenáveis quanto à sua 
escoabilidade com altos valores representando uma condição de fluxo fácil (Fitzpatrick, Barringer e Iqbal, 2004).

Para a determinação das características geométricas de silos, tremonhas e dimensões do orifício de descarga, deve-se direcionar especial atenção ao ângulo de atrito com a parede que representa o esforço de adesão entre o produto armazenado e a superfície do material da parede. O conhecimento do ângulo de atrito com a parede $\left(\varnothing_{\mathrm{w}}\right)$ é essencial para projetos estruturais e de estabilidade de silos nos quais devem ser garantidas descargas seguras e consistentes (Iqbal \& Fitzpatrick, 2006).

Em vista desses pressupostos, objetivou-se com o presente trabalho determinar as propriedades físicas e de fluxo de três tipos de rações avícolas comerciais, classificá-las quanto ao índice de fluxo de Jenike e analisar seus efeitos nas características geométricas de tremonhas para dois materiais de parede.

\section{MATERIAL E MÉTODOS}

A pesquisa foi desenvolvida no Laboratório de Construções Rurais e Ambiência (LaCRA) do Centro de Tecnologias e Recursos Naturais da Universidade Federal de Campina Grande (CTRN/UFCG), Campina Grande-PB, entre os meses de outubro e dezembro de 2005.

\section{Produtos utilizados}

Os produtos sólidos testados foram três rações avícolas comercializadas no Estado da Paraíba. Para um melhor entendimento e condução do experimento, foi denominado de Ração A aquela destinada à fase inicial de criação, de Ração B aquela para as fases de crescimento e engorda e de Ração C aquela para a fase de terminação das aves, tendo em vista que para cada fase de produção avícola os componentes das rações e suas proporções são variados.

\section{Propriedades físicas e de fluxo}

O teor de umidade (w) das rações foi encontrado pela pesagem de uma amostra de $10 \mathrm{~g}$ de cada produto antes e após a secagem em estufa a $105^{\circ} \mathrm{C}$ por $24 \mathrm{~h}$. As amostras foram analisadas em triplicata para cada ração sendo o resultado final expresso em base úmida $\left(\mathrm{w}_{\mathrm{b}}\right)$. A dimensão máxima das partículas $\left(\mathrm{d}_{\mathrm{m}}\right)$ foi determinada pelo método de peneiramento de amostra de $500 \mathrm{~g}$. Para a determinação do teor de gordura das rações $\left(\mathrm{C}_{\mathrm{f}}\right)$, adotouse o método de Randall (1974).

O procedimento adotado para a determinação das propriedades de fluxo das rações foi o recomendado pela British Materials Handling Board (1985), utilizando o Aparelho de Cisalhamento de Jenike (Figura 2) permitindo construir gráficos de tensão normal versus cisalhamento (Figura 3). Com isso, foi possível traçar círculos de tensões de Mohr responsáveis por determinar a Tensão Principal de Consolidação $\left(\sigma_{M}\right)$ e a Tensão Não Confinada de Deslizamento $\left(\sigma_{\mathrm{C}}\right)$.

Ainda na Figura 3, foi possível determinar o ângulo de atrito interno $(\delta)$, o ângulo efetivo de atrito interno $(\varnothing)$ e a Coesão (C) das rações para os diferentes níveis de carga adotados (Tabela 1 ).

Para a determinação do ângulo de atrito com a parede $\left(\varnothing_{\mathrm{w}}\right)$, adotou-se as recomendações da British Materials Handling Board (1985) sendo os níveis de cargas iguais a $50 \mathrm{~N}, 40 \mathrm{~N}, 30 \mathrm{~N}, 20 \mathrm{~N}, 10 \mathrm{~N}$ e $4,4 \mathrm{~N}$. As superfícies utilizadas nos ensaios foram as paredes de aço liso e rugoso por serem os materiais de maior possibilidade de uso na construção de silos.

Para a obtenção do Índice de fluxo (ff $)$, utilizou-se o valor médio das razões entre $\left(\sigma_{\mathrm{M}}\right)$ e $\left(\sigma_{\mathrm{C}}\right)$, classificando cada produto ensaiado de acordo com estudos de Jenike (1964).
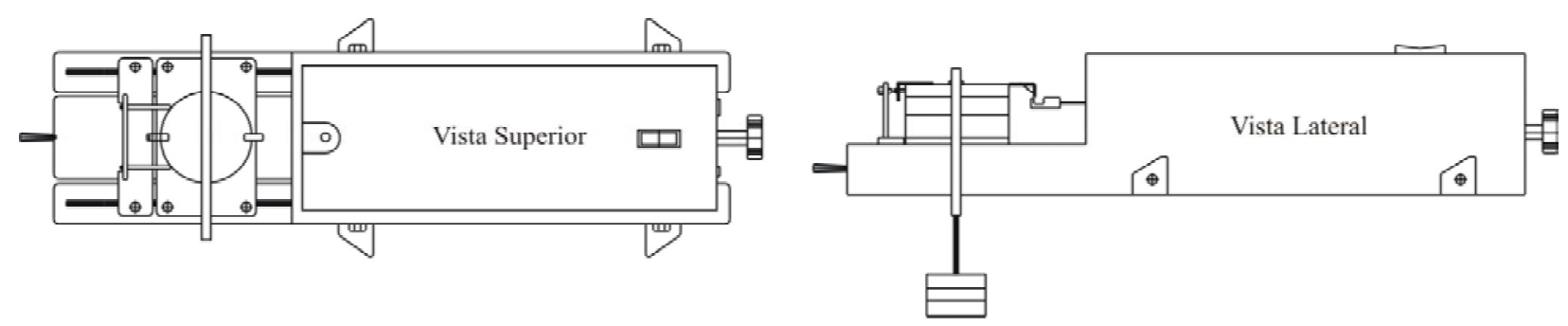

FIGURA 2 - Aparelho de Cisalhamento de Jenike. 


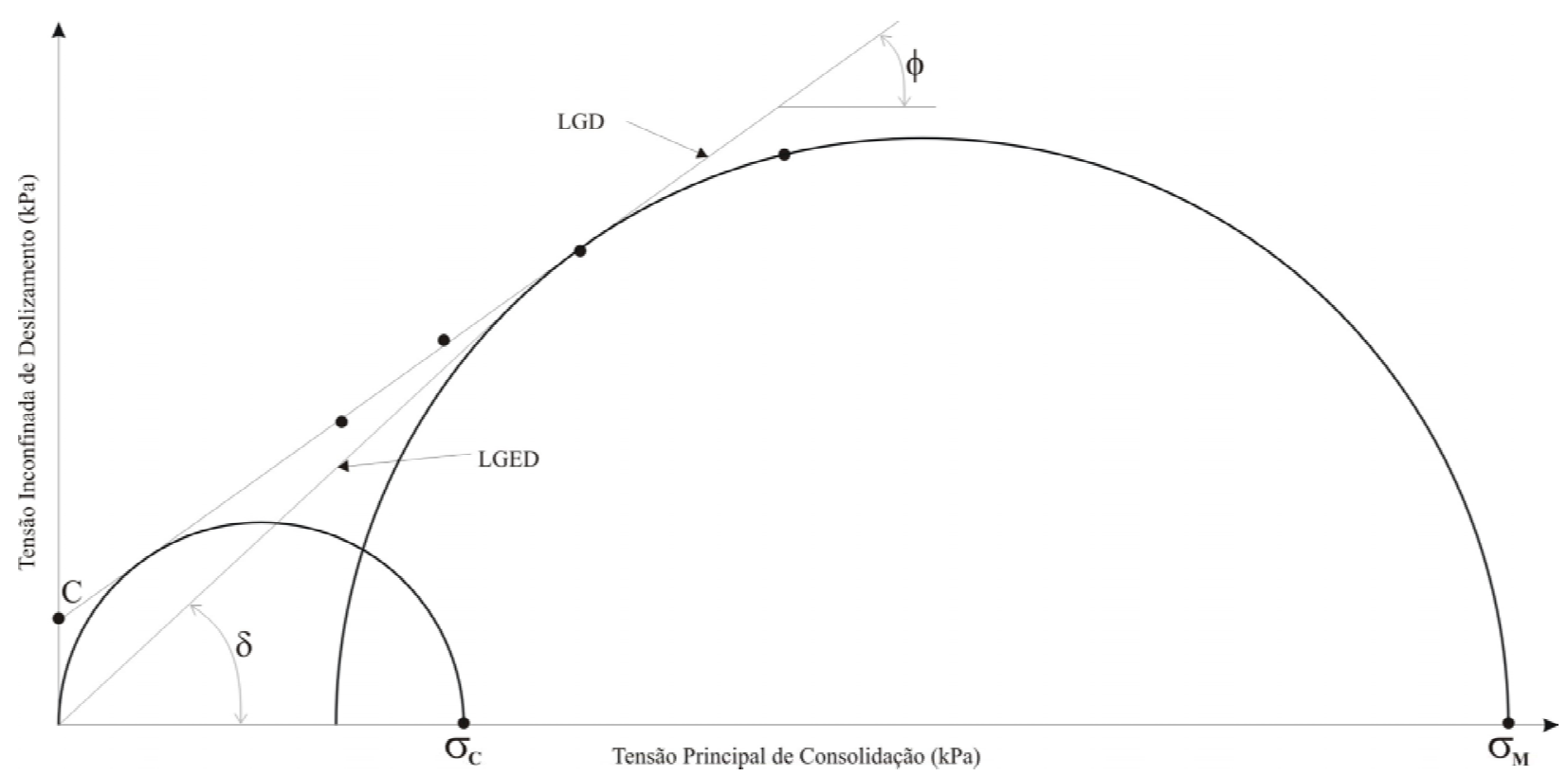

FIGURA 3 - Círculos de tensões de Mohr utilizado para determinação das propriedades.

TABELA 1 - Níveis de carga utilizadas nos ensaios de cisalhamento.

\begin{tabular}{cccc}
\hline Pré-cisalhamento (N) & \multicolumn{3}{c}{ Cisalhamento (N) } \\
\hline 100 & 70 & 50 & 35 \\
70 & 50 & 35 & 20 \\
50 & 35 & 20 & 10 \\
\hline
\end{tabular}

TABELA 2 - Classificação do tipo de fluxo de produtos sólidos armazenáveis.

\begin{tabular}{lc}
\hline Tipo de fluxo & Índice de fluxo $\left(\mathbf{f f}_{\mathbf{c}}\right)$ \\
\hline Sem fluxo & $\mathrm{ff}_{\mathrm{c}}<1$ \\
Muito coesivo & $1<\mathrm{ff}_{\mathrm{c}}<2$ \\
Coesivo & $2<\mathrm{ff}_{\mathrm{c}}<4$ \\
Fácil & $4<\mathrm{ff}_{\mathrm{c}}<10$ \\
Livre & $\mathrm{ff}_{\mathrm{c}}>10$ \\
\hline
\end{tabular}

A determinação da Função fluxo do produto (FF) foi realizada plotando-se os pontos da $\sigma_{\mathrm{M}}$ versus $\sigma_{\mathrm{C}}$ obtidos através do conhecimento dos círculos de tensões de Mohr. Com a interceptação de FF pelo
Fator fluxo da tremonha (ff), determinou-se a tensão crítica $\left(\sigma_{c r}\right)$ a fim de se evitar formação de arcos coesivos que provocam obstrução durante a descarga (Figura 4). 


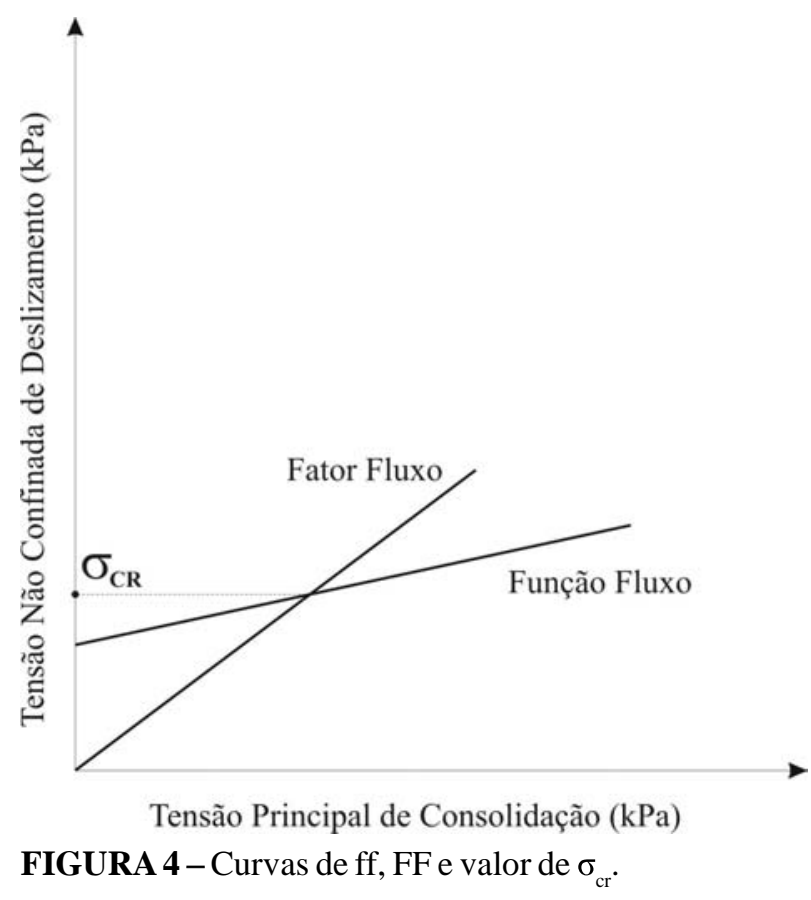

O orifício mínimo de descarga (D) foi calculado conforme expressão proposta por Jenike (1964) o qual é o produto entre $\left(\sigma_{\mathrm{cr}}\right)$ para cada material de parede e $\mathrm{H}(\theta)$ (valor em uma função do ângulo de inclinação da tremonha cônica) dividido pelo peso específico consolidado $(\gamma)$.

$$
\mathrm{D}=\frac{\mathrm{H}(\theta) \sigma_{\mathrm{cr}}}{\gamma}
$$

O ângulo de inclinação mínimo da tremonha com a horizontal $\left(\theta_{\mathrm{m}}\right)$ de forma que fosse assegurado o fluxo do produto foi determinado por meio da aplicação da equação desenvolvida por Enstad (1981). Todos os ensaios foram realizados apenas para a obtenção das propriedades instantâneas de fluxo à temperatura ambiente $\left(24^{\circ} \mathrm{C}\right)$ e umidade relativa do ar em torno de $67 \%$.

\section{RESULTADOS E DISCUSSÃO}

Na Tabela 3 estão dispostos os dados de teor de umidade $(w)$, dimensão máxima das partículas $\left(\mathrm{d}_{\mathrm{m}}\right)$ e teor de gordura $\left(\mathrm{C}_{\mathrm{f}}\right)$ das três rações analisadas. Observa-se que a Ração A possui maior teor de umidade e menor tamanho de partículas, enquanto que a Ração B possuía maior teor de gorduras dentre os produtos estudados. Os menores valores de umidade e gorduras foram encontrados para Ração C em razão de essa ser destinada somente à finalização de produção e não às fases cruciais de crescimento e ganho de peso das aves como no caso das rações A e B.

TABELA 3 - Propriedades físicas das rações analisadas.

\begin{tabular}{cccc}
\hline Produto & $\mathbf{w}(\boldsymbol{\%})$ & $\mathbf{d}_{\mathbf{m}}(\mathbf{m m})$ & $\mathbf{C}_{\mathbf{f}}(\boldsymbol{\%})$ \\
\hline Ração A & 13 & 0,5 & 8,1 \\
Ração B & 12 & 0,6 & 8,2 \\
Ração C & 11 & 0,6 & 7,0 \\
\hline
\end{tabular}

Na Tabela 4 encontram-se os resultados das propriedades de fluxo das três rações analisadas, sendo que para o peso específico consolidado $(\gamma)$, ângulo de atrito interno $(\varnothing)$ e ângulo efetivo de atrito interno $(\delta)$, as propriedades são apresentadas em seus valores máximos e mínimos possibilitando, assim, o projeto de silos através do Método dos estados limites. Mesmo o Brasil ainda não tendo uma norma especifica de dimensionamento de silos, devemse utilizar normas internacionais para o projeto e dentre as existentes, a Australian Standard 3774 (1990) dá indicações para a utilização dos estados limites em projetos de silos.

Nota-se que o maior valor encontrado de $\mathrm{C}$ foi para a Ração B o que é comprovado pelo baixo valor de $\mathrm{ff}_{\mathrm{c}}(3,8)$ e maior limite superior para o peso específico consolidado $\left(8630 \mathrm{kN} / \mathrm{m}^{3}\right)$ dentre os produtos estudados. Segundo classificação do tipo de fluxo proposto por Jenike (1964) (Tabela 2), as Rações A e B podem ser consideradas como produtos coesivos, enquanto que a Ração C de fluxo fácil. Tal fato pode ser explicado pelas divergências entre os valores das dimensões das partículas entre as rações analisadas (Tabela 3). Sabe-se que produtos com dimensões de suas partículas reduzidas apresentam problemas de escoamento, pois a área da superfície da partícula por unidade de massa aumenta à medida que seu tamanho é reduzido proporcionando aumento nas forças de coesão. Em contrapartida a esse aumento, ocorre uma redução no índice de fluxo (ff) resultando no desenvolvimento de em um tipo de fluxo mais coesivo (Fitzpatrick, Barringer e Iqbal, 2004).

O fator que preponderantemente influenciou na classificação das rações foi o teor de gordura, pois a ração $\mathrm{C}$ que possuía menor $\mathrm{C}_{\mathrm{f}}$ certamente apresenta menores propriedades coesivas que as demais. Conseqüentemente, o $\mathrm{C}_{\mathrm{f}}$ influencia significativamente nas propriedades determinadas. 
Em adição a esse fator, pode-se contabilizar uma maior presença de líquidos nas Rações A e B o que aumenta as forças de coesão que interagem nas estruturas dos produtos. Tal fenômeno deve-se, principalmente, às forças de Van der Waals e de capilaridade e estão sempre associadas à presença de líquidos (Shamlou, 1988). Devido às diferenças nas composições e estruturas físicas das partículas de diferentes pós, a interação entre essas forças de superfície pode variar de produto para produto (Fitzpatrick, Barringer e Iqbal, 2004).

Em análise dos ângulos de atrito interno $(\varnothing)$ e efetivo $(\delta)$ (Tabela 4), os maiores valores foram encontrados para a Ração A, muito provavelmente em função de seu teor de umidade superior às das outras rações. Entretanto, um completo entendimento desse comportamento é uma tarefa difícil pelo fato de existirem elementos não considerados como conservantes, sais, ácidos, óleos e gorduras que podem exercer influências nas propriedades físicas e de fluxo de rações avícolas. Sabe-se que produtos pulverulentos orgânicos como os pós alimentícios são complexos e de difícil caracterização pelo fato de apresentar composição variada, distribuição não uniforme de partículas e presença de elementos tanto nas fases sólida, líquida e gasosa.
Na Tabela 5 estão apresentados os ângulos de atrito interno do produto com as superfícies de parede analisadas $\left(\varnothing_{\mathrm{w}}\right)$ para as três rações. Destacam-se os maiores valores para a Ração A para as duas paredes o que pode ser explicado pelo fato de produtos com partículas menores apresentarem elevados valores de $\varnothing_{\mathrm{w}}$ em função do alto contato entre a superfície específica das partículas e parede como também por possuir maior teor de gordura o que aumenta a aderência à superfície das paredes.

No Gráfico 1 encontram-se plotadas as linhas representativas às funções fluxo das três rações analisadas podendo-se destacar uma menor inclinação de FF para a Ração C vindo a confirmar sua condição de escoabilidade (fluxo fácil). Para as demais rações, as funções fluxo encontram-se com um maior ângulo de inclinação, sendo isso característico de um produto com baixa mobilidade no momento de fluxo. Ao investigarem a função fluxo de leite em pó com diferentes teores de gordura, Fitzpatrick, Iqbal, Delaney et al. (2004) encontraram comportamento semelhante de FF para as amostras com índices de fluxo abaixo de 2 (fluxo muito coesivo).

TABELA 4 - Propriedades de fluxo dos produtos analisados.

\begin{tabular}{ccccccccc}
\hline \multirow{2}{*}{ Produto } & \multirow{2}{*}{$\mathbf{C}(\mathbf{P a})$} & \multirow{2}{*}{$\mathbf{f f}_{\mathbf{c}}$} & \multicolumn{2}{c}{$\boldsymbol{\gamma}\left(\mathbf{N} / \mathbf{m}^{\mathbf{3}}\right)$} & \multicolumn{2}{c}{$\boldsymbol{\varnothing}\left(^{\circ}\right)$} & \multicolumn{2}{c}{$\boldsymbol{\delta}\left({ }^{\circ}\right)$} \\
\cline { 4 - 9 } & & & $\gamma_{\mathbf{i}}$ & $\boldsymbol{\gamma}_{\mathbf{s}}$ & $\boldsymbol{\emptyset}_{\mathbf{i}}$ & $\boldsymbol{\emptyset}_{\mathbf{s}}$ & $\boldsymbol{\delta}_{\mathbf{i}}$ & $\boldsymbol{\delta}_{\mathbf{s}}$ \\
\hline Ração A & 1025 & 4,1 & 8039 & 8307 & 41,5 & 51,0 & 47,6 & 51,8 \\
Ração B & 1596 & 3,8 & 8121 & 8630 & 35,5 & 37,5 & 42,5 & 43,6 \\
Ração C & 554 & 8,7 & 7973 & 8125 & 39,4 & 40,3 & 42,5 & 42,7 \\
\hline
\end{tabular}

Os sub-índices "i" e "s" representam os valores inferior e superior das propriedades, respectivamente.

TABELA 5 - Ângulo de atrito interno com as paredes.

\begin{tabular}{|c|c|c|c|c|}
\hline \multirow{3}{*}{ Ração } & \multicolumn{4}{|c|}{ Ângulo de atrito com a parede $\emptyset_{w}\left({ }^{\circ}\right)$} \\
\hline & \multicolumn{2}{|c|}{ Aço liso } & \multicolumn{2}{|c|}{ Aço rugoso } \\
\hline & $\emptyset_{\mathrm{wi}}$ & $\emptyset_{\mathrm{ws}}$ & $\emptyset_{w i}$ & $\emptyset_{\mathrm{ws}}$ \\
\hline A & 14,5 & 24,3 & 16,1 & 22,8 \\
\hline B & 11,0 & 17,3 & 14,2 & 21,2 \\
\hline $\mathrm{C}$ & 9,4 & 13,7 & 15,0 & 21,3 \\
\hline
\end{tabular}

Os sub-índices "i" e "s" representam os valores inferior e superior das propriedades, respectivamente.

Ciênc. agrotec., Lavras, v. 31, n. 3, p. 851-859, maio/jun., 2007 
Nota-se, ainda, para Ração A maior inclinação de FF com a horizontal devido, provavelmente, a presença de maior teor de umidade e gordura da mesma (Tabela 3) já que é confirmado que a presença de água em um produto pode afetar significativamente sua escoabilidade e que, quanto maior o teor de umidade, mais coesivo se tornará e mais difícil será seu fluxo.

Nas Tabelas 6, 7 e 8 encontram-se os valores de fator fluxo da tremonha (ff), ângulo de inclinação mínimo da tremonha com a horizontal $(\theta \mathrm{m})$, Tensão crítica $\left(\sigma_{\mathrm{Cr}}\right)$, Coeficiente da tremonha cônica em função de sua inclinação $\mathrm{H}(\theta)$ e orifício de descarga mínimo (D).

Os maiores valores de inclinação da tremonha dentre os três produtos ensaiados foram registrados para a Ração A tanto para a parede de aço liso quanto rugoso. Já para a Ração C, foram registrados os menores ângulos apesar de ser notada para esse produto a maior variação de ângulo de inclinação da tremonha entre as paredes de aço liso e rugoso $\left(10^{\circ}\right)$. Isso demonstra que, apesar do atrito com a parede ser uma importante variável na determinação do ângulo mínimo da tremonha para que ocorra o fluxo (Iqbal \& Fitzpatrick, 2006), os valores encontrados não produziram variação significativa da inclinação da tremonha entre os produtos estudados.

Em análise ao diâmetro mínimo orifício de descarga, pode-se ressaltar que os maiores valores foram encontrados para a Ração C, apesar de a mesma apresentar o maior índice de fluxo. Segundo Fitzpatrick, Barringer e Iqbal, (2004), isso pode ser explicado pelo fato de alguns produtos de fluxo fácil produzirem elevados valores de tensão crítica em função da extrapolação das linhas de FF, o que pode gerar valores superestimados ou conservativos.

É recomendável que se façam determinações das propriedades dos produtos que se pretende armazenar em silos verticais a fim de determinar com exatidão a faixa de variação dessas propriedades e dessa forma, dimensionar o orifício de descarga para que tenha o tipo de fluxo dentro do padrão esperado para que não ocorra obstrução do escoamento por motivos de formação de abóbadas ou efeito tubo quando se deseja o fluxo de funil (Nascimento, 1996).

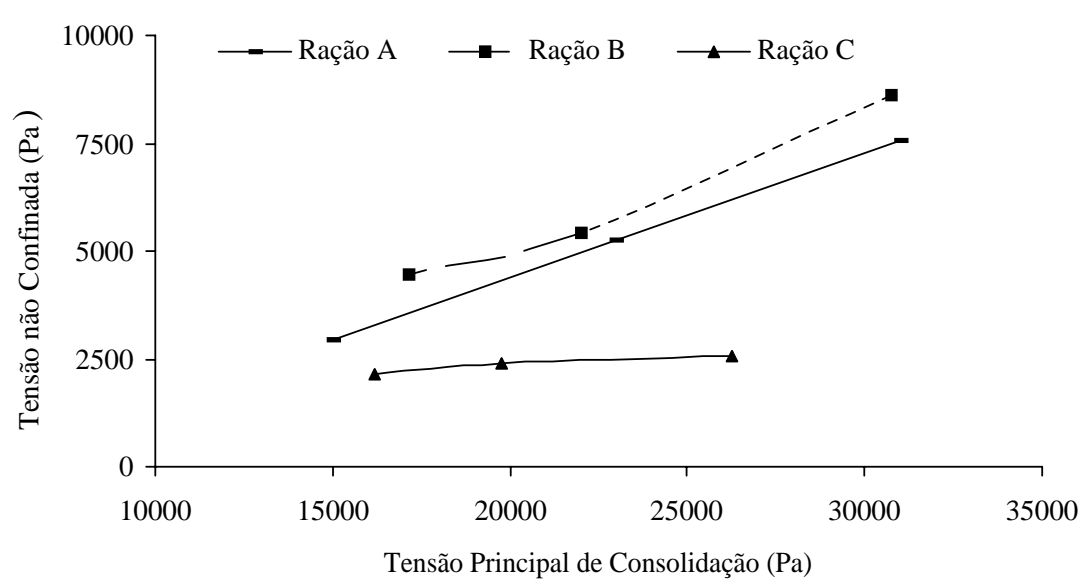

GRÁFICO 1 - Função fluxo (FF) das três rações analisadas.

TABELA 6 - Características geométricas da tremonha cônica para a Ração A.

\begin{tabular}{cccccc}
\hline & \multicolumn{5}{c}{ Aço liso } \\
\cline { 2 - 6 } Ração A & $\mathrm{ff}$ & $\theta \mathrm{m}\left(^{\circ}\right)$ & $\sigma_{\mathrm{cr}}(\mathrm{Pa})$ & $\mathrm{H}(\theta)$ & $\mathrm{D}(\mathrm{m})$ \\
& 1,23 & 69 & 1018 & 2,34 & 0,28 \\
\cline { 2 - 6 } & $\mathrm{ff}$ & $0 \mathrm{Aço} \mathrm{rugoso}$ & $\mathrm{D}(\mathrm{m})$ \\
& 1,21 & 73 & $\sigma_{\mathrm{cr}}(\mathrm{Pa})$ & $\mathrm{H}(\theta)$ & 0,29 \\
\hline
\end{tabular}


TABELA 7 - Características geométricas da tremonha cônica para a Ração B.

\begin{tabular}{cccccc}
\hline & \multicolumn{5}{c}{ Aço liso } \\
\cline { 2 - 6 } Ração B & $\mathrm{ff}$ & $\theta \mathrm{m}\left({ }^{\circ}\right)$ & $\sigma_{\mathrm{cr}}(\mathrm{Pa})$ & $\mathrm{H}(\theta)$ & $\mathrm{D}(\mathrm{m})$ \\
& 1,41 & 60 & 771 & 2,44 & 0,22 \\
\cline { 2 - 6 } & & Aço rugoso & $\mathrm{H}(\theta)$ & $\mathrm{D}(\mathrm{m})$ \\
& $\mathrm{ff}$ & $\theta \mathrm{m}\left(^{\circ}\right)$ & $\sigma_{\mathrm{cr}}(\mathrm{Pa})$ & 2,38 & 0,21 \\
\hline
\end{tabular}

TABELA 8 - Características geométricas da tremonha cônica para a Ração C.

\begin{tabular}{cccccc}
\hline & \multicolumn{5}{c}{ Aço liso } \\
\cline { 2 - 6 } Ração C & $\mathrm{ff}$ & $\theta \mathrm{m}\left(^{\circ}\right)$ & $\sigma_{\mathrm{cr}}(\mathrm{Pa})$ & $\mathrm{H}(\theta)$ & $\mathrm{D}(\mathrm{m})$ \\
& 1,45 & 55 & 1655 & 2,53 & 0,52 \\
\cline { 2 - 6 } & $\mathrm{ff}$ & Aço rugoso & $\mathrm{D}(\mathrm{m})$ \\
& 1,4 & $6 \mathrm{~m}\left({ }^{\circ}\right)$ & $\sigma_{\mathrm{cr}}(\mathrm{Pa})$ & $\mathrm{H}(\theta)$ & 0,48 \\
\hline
\end{tabular}

\section{CONCLUSÕES}

Concluiu-se que somente a Ração $\mathrm{C}$ não é um produto de característica coesiva. Para o dimensionamento geométrico da tremonha, a ração A apresentou os maiores valores de inclinação da tremonha enquanto que para o orifício de descarga, a ração $\mathrm{C}$ foi a que apresentou valores mais elevados. Tremonhas metálicas de silo para armazenamento de ração avícola deve ter inclinação mínima das paredes de $70^{\circ}$ combinado com um orifício de descarga suficiente para garantir fluxo de massa e, conseqüentemente, não haver segregação durante a descarga.

\section{REFERÊNCIAS BIBLIOGRÁFICAS}

AUSTRALIAN STANDARD 3774: Loads on bulk containers. Sydney: 1990.

BENINK, E.J. Flow and stress analysis of cohesioless bulk materials in silos related to codes. 1989. 162p. Thesis Universiteit Tweste, Netherlands, 1989.

BRITISH MATERIALS HANDLING BOARD. Draft code of practice for the design of silos, bins, bunkers and hoppers. London: 1985.

ENSTAD, G. G. A novel theory on the arching and doming in mass flow hoppers. The Michelsen Institute, Bergen, 1981. 125p.
FITZPATRICK, J. J.; BARRINGER, S. A.; IQBAL, T. Flow property measurement of food powders and sensitivity of Jenike's hopper design methodology to the measured values. Journal of Food Engineering, Elsevier Science, n.61, p.399-405, 2004.

FITZPATRICK, J. J.; IQBAL, T.; DELANY, C. et al. Effect of powder properties and storage conditions on the flowability of milk powders with different fat contents. Journal of Food Engineering, Elsevier Science, n.64, p.435444, 2004.

IQBAL, T. \& FITZPATRICK, J. J. Effect of powder properties on the wall friction characteristics of three food powders. Journal of Food Engineering, Elsevier Science, n.72, p.273280, 2006.

JENIKE, A.W. Storage and flow of silos. Salt Lake City. University of Utah. Bulletin 123. Engineering Experiment Station (1964).

KNOWTON, T. M.; CARSON, J. W.; KLINZING et al. The importance of storage, transfer and collection. Chemical Engineering Progress, Elsevier Science, n.90, p.44-54, 1994.

NASCIMENTO, J. W. B. Estudos de silos metálicos prismáticos para fábricas de ração. 1996. Tese (Doutorado em Engenharia de Estruturas) - Escola de Engenharia de São Carlos, Universidade de São Paulo, São Carlos, 1996. 
NÓBREGA, M. V. Análise de vazão e fluxo de ração e fluxo de ração avícola em silos prismáticos com descarga excêntrica. 2003. Dissertação (Mestrado em Engenharia Agrícola) - Universidade Federal de Campina Grande, Campina Grande, 2003. 88p.

RANDALL, E.L. Improved method for fat and oil analysis by a new process of extraction. Journal of the Analytical of Official Agricultural Chemists. v.57, n.5, p.1167-1168. 1974.

ROBERTS, A. W. Storage, flow and handling of bulk solids. Newcastle: Department of Mechanical Engineering, University of Newcastle, 1987. 612p.
SCHUBERT, H. Food particle technology. Part I: Properties of particles and particulate food systems. Journal of Food Engineering, Elsevier Science, n.6, p.132, 1987.

SHAMLOU, P. A. Handling of bulk solids - theory and practice. London, UK: Butterworths, 1988.

TEUNOU, E.; FITZPATRICK, J. J.; SYNNOTT, E. C. Characterisation of food powder flowability. Journal of Food Engineering, Elsevier Science, n.39, p.31-37, 1999. 